\title{
Elevated High Density Lipoprotein Cholesterol Levels Correlate with Decreased Apolipoprotein A-I and A-II Fractional Catabolic Rate in Women
}

\author{
Eliot A. Brinton, Shlomo Eisenberg, * and Jan L. Breslow \\ Laboratory of Biochemical Genetics and Metabolism, The Rockefeller University, New York 10021; and \\ *Department of Medicine B, Hadassah University Hospital, Jerusalem, Israel
}

\begin{abstract}
High levels of HDL-cholesterol (HDL-C) protect against coronary heart disease susceptibility, but the metabolic mechanisms underlying elevated HDL-C levels are poorly understood. We now report the turnover of isologous radioiodinated HDL apolipoproteins, apo A-I and apo A-II, in 15 female subjects on a metabolic diet with HDL-C levels ranging from 51 to $122 \mathrm{mg} / \mathrm{dl}$. The metabolic parameters, fractional catabolic rate (FCR) and absolute synthetic rate (SR), were determined for apo $A-I$ and apo $A-I I$ in all subjects.

There was an inverse correlation between plasma HDL-C and the FCR of apo A-I and apo A-II $(r=-0.75, P<0.001$, and $r=-0.54, P=0.036$, respectively), but no correlation with the SR of either apo A-I or apo A-II $(r=0.09$, and $r=-0.16$, respectively, both $P=N S)$. Apo A-I levels correlated inversely with apo A-I FCR $(r=-0.64, P=0.01)$ but not with apo A-I SR $(r=0.30, P=N S)$. In contrast, plasma levels of apo A-II did not correlate with apo A-II FCR $(r=-0.38, P=0.16)$, but did correlate with apo A-II SR $(r=0.65, P=0.009)$. Further analysis showed that apo A-I and apo A-II FCR were inversely correlated with the HDL-C/apo A-I + A-II ratio $(r=-0.69$ and $-0.61, P=0.005$ and 0.015 , respectively).

These data suggest that: $(a)$ low HDL apolipoprotein FCR is the predominant metabolic mechanism of elevated HDL-C levels; (b) apo A-I FCR is the primary factor in controlling plasma apo A-I levels, but apo A-II SR is the primary factor controlling plasma apo A-II levels; (c) low HDL apolipoprotein FCR is associated with a lipid-rich HDL fraction. These findings elucidate aspects of HDL metabolism which contribute to high HDL-C levels and which may constitute mechanisms for protection against coronary heart disease.
\end{abstract}

\section{Introduction}

High HDL-cholesterol (HDL-C) ${ }^{1}$ levels are a "protective" risk factor for coronary heart disease (1). Women have higher HDL-C levels than men on average (2), and this is believed to

Address reprint requests to Dr. Brinton, Box H29, The Rockefeller University, 1230 York Avenue, New York, NY 10021.

Received for publication 8 July 1988 and in revised form 20 March 1989.

1. Abbreviations used in this paper: $\mathrm{CHD}$, coronary heart disease; FCR, fractional catabolic rate; FPLC, fast protein liquid chromatography; HDL-C, high density lipoprotein-cholesterol; HL, hepatic lipase; LPL, lipoprotein lipase; SR, synthetic rate.

J. Clin. Invest.

(c) The American Society for Clinical Investigation, Inc.

0021-9738/89/07/0262/08 \$2.00

Volume 84, July 1989, 262-269 account for some of their advantage regarding atherosclerosis risk. Unfortunately, little is known about the metabolic basis underlying the high HDL-C state in women. HDL apolipoprotein turnover studies are the established method for studying in vivo metabolism of $\mathrm{HDL}$, but there have been published only four such studies of women with high HDL-C and they report on only a total of five women with HDL-C levels above the 80th percentile for age and sex (3-6). Because of the small number of subjects, usually being compared with only a few controls, it has been difficult to draw conclusions about the metabolic basis of high HDL-C.

In the current report, we have studied in vivo HDL apolipoprotein turnover in 15 individuals with HDL-C levels ranging from normal to very elevated (eight subjects above the 80th percentile). Since sex hormone therapy and gender are known to affect HDL-C levels and HDL apolipoprotein turnover parameters, we included only women and have excluded those taking exogenous estrogen. The subjects were studied on a metabolic diet, with a fixed content of fat and carbohydrate and without alcohol ingestion, to minimize variability from dietary influences. We found that HDL-C levels correlated inversely with the fractional catabolic rate (FCR) of both apo A-I and apo A-II but not with the absolute synthetic rates (SR) of either of these apoproteins.

\section{Methods}

Subjects. 15 female subjects were recruited from three sources: (a) patients from the clinic of the Laboratory of Biochemical Genetics and Metabolism; $(b)$ healthy, adult volunteers working on the staff at Rockefeller University or at neighboring institutions; (c) undergraduate students on a work-study program. All subjects were free from renal, thyroid, and immunologic disorders by history and laboratory screening. All but one of the subjects were also free from hepatic disease. This subject (No. 1) had a history of hepatic porphyria, which had been clinically silent on daily treatment with luteinizing hormone-releasing hormone antagonist for over 1 yr before the study. On this regimen, she had amenorrhea with estradiol levels in the borderline low to low-normal range. During the study she continued the treatment. However, it was later discontinued without a significant change in her HDL-C level. This suggested that the drug had no significant effect on her apo-HDL turnover. Subject 2 had partial hypopituitarism from successful removal of a craniopharyngioma several years earlier and was taking only physiologic replacement doses of hydrocortisone and vasopressin at the time of the study. She also had amenorrhea and mild symptoms of estrogen deficiency and was taking no estrogen supplements. None of the other subjects were taking medications known to alter lipid levels. The clinical aspects of these studies were approved by the Institutional Review Board of Rockefeller University, and informed consent was obtained from the subjects in all cases.

Apolipoprotein preparation and labeling. Plasma was taken from healthy donors who had normal lipid levels and whose plasma was negative on screening for hepatitis B and HIV. HDL, $d=1.063-1.21$ $\mathrm{g} / \mathrm{ml}$, was prepared by sequential isopycnic ultracentrifugation for 
18-24 h at 50,000 rpm in a $60 \mathrm{Ti}$ rotor (Beckman Instruments, Inc., Fullerton, $\mathrm{CA}$ ) at $4^{\circ} \mathrm{C}$ using solid $\mathrm{KBr}$ for sample density adjustment. The HDL was dialyzed against $0.15 \mathrm{M} \mathrm{NaCl}, 1 \mathrm{mM} \mathrm{Na} \mathrm{m}_{2}$ EDTA, pH 7.4 , and then delipidated by the following method. $1 \mathrm{ml}$ of $\mathrm{HDL}$ preparation $(4-20 \mathrm{mg}$ protein $/ \mathrm{ml}$ ) was added dropwise to $5 \mathrm{ml}$ of acetone/ethanol $1: 1$ at $-15^{\circ} \mathrm{C}$ in a polypropylene tube while vortexing. Another $8 \mathrm{ml}$ of the acetone/ethanol was added and the tube inverted to mix the contents thoroughly. After standing at $-15^{\circ} \mathrm{C}$ for $1 \mathrm{~h}$ the mixture was spun at $2500 \mathrm{rpm}$ at $4^{\circ} \mathrm{C}$ for $5 \mathrm{~min}$ and the supernatant discarded. The precipitate was vortexed with $5 \mathrm{ml}$ of acetone/ethanol $\left(1: 1,-15^{\circ} \mathrm{C}\right)$, and $8 \mathrm{ml}$ of acetone/ethanol was added. After standing as before for $1 \mathrm{~h}$ the mixture was centrifuged for $20 \mathrm{~min}$ and the supernatant was again discarded. If needed to remove any traces of yellow in the precipitate this procedure was repeated a third time. Finally, the precipitate was vortexed with $5 \mathrm{ml}$ of diethyl ether. The mixture was centrifuged as before, the supernatant aspirated, and the precipitate dried under $\mathrm{N}_{2}$ and stored at $4^{\circ} \mathrm{C}$ until used. To purify the HDL apolipoproteins, the precipitate was dissolved in $0.05 \mathrm{M}$ Tris $\mathrm{HCl}, \mathrm{pH}$ 8.2 , in freshly deionized $6 \mathrm{M}$ urea. This solution was passed through a $0.45-\mu \mathrm{m}$ filter and applied to an anion exchange column, Mono $\mathrm{Q}$ (fast protein liquid chromatography, Pharmacia, Inc., Piscataway, NJ). Peaks corresponding to apo A-I and apo A-II were eluted using a Tris- $\mathrm{HCl}$ gradient, $0.05-0.5 \mathrm{M}, \mathrm{pH} 8.2$, in $6 \mathrm{M}$ urea. Apo A-I and apo A-II were further purified by gel filtration chromatography on a Superose 12 column (fast protein liquid chromatography, Pharmacia, Inc.), in $0.05 \mathrm{M}$ Tris $\mathrm{HCl}$, pH 8.2, in $6 \mathrm{M}$ urea. Purity was judged by overloaded silver-stained SDS-PAGE with a $10-15 \%$ acrylamide gradient (SDS-PAGE, Phast system, Pharmacia, Inc.). The purified apo A-I or apo A-II solution was either used promptly for iodination or was dialyzed against $1 \mathrm{mM}$ ammonium bicarbonate, lyophilized and stored at $-15^{\circ} \mathrm{C}$ until used.

Radioiodination was performed by the Bilheimer modification (7) of the McFarlane method (8), with the apolipoprotein dissolved in the same buffer as used for column chromatography. After iodination, the protein solution was dialyzed against $0.15 \mathrm{M} \mathrm{NaCl}, 1 \mathrm{mM} \mathrm{Na} \mathrm{FD}_{2}$ TA, $\mathrm{pH}$ 7.4. Human serum albumin was added to a final concentration of 8 $\mathrm{mg} / \mathrm{ml}$, and the solution was put through a $0.22-\mu \mathrm{m}$ filter. The filtrate was tested for pyrogens by injection into rabbits or by the Limulus test (Pyrotell Limulus amebocyte lysate, Associates of Cape Cod Woods Hole, MA) (9), and sterility was tested by culture. The radiolabeled apo A-I and apo A-II contained on average $0.5 \mathrm{~mol}$ of iodine per mol of apolipoprotein. A previous study suggests that twice this degree of iodination has little effect on physical properties of apo A-I (10). Over $99 \%$ of the radioactivity was precipitable by $17 \%$ trichloroacetic acid, and $>95 \%$ of the counts were within the specific apolipoprotein band on SDS/PAGE.

Kinetic studies. The subjects were admitted to The Rockefeller University Hospital inpatient ward and kept on a natural food metabolic diet for $4 \mathrm{wk}$. The diet had a caloric distribution of $42 \%$ fat, $43 \%$ carbohydrate, and $15 \%$ protein. The fat content corresponded to the 50th percentile of previous American intake according to the Lipid Research Clinics (LRC) study (11), and to the 75th percentile of the current American consumption according to the National Health and Nutrition Examination Survey (NHANES) II survey (12). The diet had a polyunsaturated to saturated fat ratio of 0.1 and contained $215 \mathrm{mg}$ cholesterol per 1,000 calories. Caloric need was estimated by the Harris-Benedict (13) equation, with adjustment for physical activity (14), and caloric intake was not altered during the study. After the first $2 \mathrm{~d}$ body weight remained constant. No alcohol intake was allowed and subjects were instructed to maintain their usual level of physical activity.

After 2 wk of equilibration on the metabolic diet, the subjects received $25 \mu \mathrm{Ci}$ each of isologous radioiodinated apo A-I and apo A-II $\left({ }^{125} \mathrm{I}\right.$ and ${ }^{131} \mathrm{I}$, respectively, or vice versa) by intravenous bolus injection. Previous studies in two separate laboratories have demonstrated that radiolabeling of purified HDL apolipoproteins gives results similar to that obtained by protein labeling of intact $\operatorname{HDL}(5,15)$. This similarity is due to the rapid association of free HDL apolipoproteins with plasma HDL in vivo. To allow for thorough mixing of the tracers with
HDL in the plasma compartment, the first blood sample was taken after $10 \mathrm{~min}$. Blood was then taken at $4,12,24$, and $36 \mathrm{~h}$ and then daily until $14 \mathrm{~d}$. All except the 4-, 12-, and 36-h samples were taken after an overnight fast of $12 \mathrm{~h}$. Blood was drawn into $\mathrm{Na}_{2}$ EDTA ( $4 \mathrm{mM}$ final concentration), immediately placed at $4^{\circ} \mathrm{C}$, and spun at $2000 \mathrm{rpm}$ for $20 \mathrm{~min}$ to separate the plasma. Using a volumetric pipet, $1.0-\mathrm{ml}$ aliquots were taken in quadruplicate from the 10-min sample and in duplicate from all other samples for double isotope counting with an Auto-gamma counter (Packard Instrument Co., Inc., Downers Grove, IL). Since all subjects were in steady state with regard to apo A-I and apo A-II levels, the radioactive decay curve was plotted directly from the die-away of plasma counts. The FCR was calculated from the plasma die-away by the Matthews method (16). Absolute transport or SR was calculated by multiplying the FCR by the plasma pool (apolipoprotein level times plasma volume) and dividing by the body weight. Plasma volume was determined by isotope dilution at the 10-min point.

To show that the iodinated apo A-I and apo A-II associated with HDL, in each study extra aliquots of plasma were taken $10 \mathrm{~min}$ and 7 and $14 \mathrm{~d}$ after injection. Three fractions were prepared by ultracentrifugation, $d<1.063,1.063<d<1.21$, and $d>1.21$. The density distribution of radiolabel was calculated as a percentage of total counts, and the results for the 10-min, 7-, and 14-d samples were averaged. These density fractions contained $1.7 \%, 89.0 \%$, and $9.5 \%$ of the apo A-I and $1.4 \%, 91.6 \%$, and $7.3 \%$ of the apo A-II label, respectively. The results did not differ significantly by time of sampling during the 14-d period.

Lipid, lipoprotein, and apolipoprotein determinations. On days 1 , $3,7,10$, and 14 of the turnover period, plasma was obtained after a 12-h overnight fast for measurement of lipid, lipoprotein, and apolipoprotein levels. Lipid and lipoprotein measurements were done on fresh, unfrozen specimens, while aliquots of plasma were immediately frozen at $-70^{\circ} \mathrm{C}$ for apolipoprotein determinations at a later date. Total cholesterol and triglycerides were determined enzymatically using Boehringer Mannheim (Indianapolis, IN) kits. HDL-C was determined after apo B-containing lipoproteins were precipitated by the dextran sulfate method (17). LDL plus HDL-C was determined on the infranatant after removing VLDL-C by airfuge ultracentrifugation (Beckman Instruments, Inc.). LDL-C was determined by subtracting the HDL-C from the cholesterol in the infranatant. VLDL-C was determined by subtracting the cholesterol in the infranatant from the total cholesterol. Cholesterol and HDL-C determinations were standardized by the Lipid Standardization Program of the Centers for Disease Control, Atlanta, Georgia (18).

Frozen aliquots of plasma were assayed for apo A-I and apo A-II levels. Apo A-I levels were assayed by sandwich ELISA. A polyclonal goat antibody to human apo A-I (generously supplied by Dr. Peter Herbert, Brown University, Providence, RI) was purified by ammonium sulfate precipitation (19) and apo A-I affinity chromatography (CNBr sepharose, Pharmacia, Inc., using method of the manufacturer) and diluted 1:2,000 in coating buffer consisting of $15 \mathrm{mM} \mathrm{Na}_{2} \mathrm{CO}_{3}, 35$ $\mathrm{mM} \mathrm{NaHCO}_{3}$, and $3 \mathrm{mM} \mathrm{NaN}_{3}, \mathrm{pH} 9.6$ (made fresh weekly), to a final concentration of $2.5 \mu \mathrm{g}$ antibody protein $/ \mathrm{ml}$. Microtiter plates (NUNC Immuno Plate I) were incubated overnight at $4^{\circ} \mathrm{C}$ with the antibody. The plates were then washed three times in Tween 20/phosphate-buffered saline solution, 1:2,000 vol/vol, $\mathrm{pH} 7.4$ (Tween-PBS) using a Titertek Microplate Washer 120 (Flow Laboratories, Inc., McLean, VA). After washing, nonspecific binding sites were blocked by incubating the wells with bovine serum albumin (BSA) fraction $\mathbf{V}$ (Sigma Chemical Co., St. Louis, MO) $1 \mathrm{~g} / \mathrm{dl}$ in PBS for $1 \mathrm{~h}$ at $37^{\circ} \mathrm{C}$. The plates were washed as above and then plasma samples were added after serial dilution in Tween-PBS containing BSA $1 \mathrm{~g} / \mathrm{dl}$. Dilutions were made with a Cetus Pro/Pette autodilutor (Perkin-Elmer Corp., Norwalk, CT) in the range of $1: 500$ to $1: 2,000$ to bring at least two assay points within the linear range. After a $2-\mathrm{h}$ incubation at $37^{\circ} \mathrm{C}$, the plates were washed, and incubated for $2 \mathrm{~h}$ at $37^{\circ} \mathrm{C}$ with the polyclonal goat antibody to human apo A-I ( $3 \mu \mathrm{g}$ protein/ml Tween-PBS BSA solution) conjugated with alkaline phosphatase by the one-step glutaraldehyde method (20). The plates were then washed and incubated with phos- 
phatase substrate 104 (Sigma Chemical Co.), freshly dissolved at a concentration of $1 \mathrm{mg} / \mathrm{ml}$ in $0.5 \mathrm{mM} \mathrm{MgCl}_{2}-6 \mathrm{H}_{2} \mathrm{O}, 3 \mathrm{mM} \mathrm{NaN}_{3}, \mathrm{pH}$ 9.8. After $30-60 \mathrm{~min}$ in subdued light at room temperature, color development was read at $410 \mathrm{~nm}$ in a Microplate Reader MR600 (Dynatech Precision Sampling Corp., Baton Rouge, LA). Assays were standardized with a reference serum pool from the Centers for Disease Control and two frozen control sera, whose apo A-I levels had been determined by three independent laboratories (Brown University, U. S. Department of Agriculture Human Nutrition Center on Aging, and Northwest LRC). The entire assay was rejected if the control samples were more than $15 \%$ from the target values. The coefficient of variation between assays was $<15 \%$ and, within assays, $<8 \%$. Apo A-II levels were determined in the Northwest LRC laboratories by a radioimmunoassay based on a radial immunodiffusion assay (21). Over the 2-wk turnover period, no temporal trends were observed in the lipid, lipoprotein, and apolipoprotein levels and the mean of all five determinations was used in the data analysis.

Postheparin lipase activities. After $11 \mathrm{~d}$ on the $42 \%$ fat diet and $3 \mathrm{~d}$ before isotope injection, a postheparin lipase test was performed. Heparin sodium for injection, $1,000 \mathrm{U} / \mathrm{ml}$ (from porcine intestinal mucosa, Organon, Diagnostics, Inc., West Orange, NJ), was administered by intravenous bolus in a dose of $60 \mathrm{U} / \mathrm{kg}$ body weight. $15 \mathrm{~min}$ later, blood was drawn into tubes with $\mathrm{Na}_{2}$ EDTA, immediately placed on ice, and spun at $2000 \mathrm{rpm}$ for $20 \mathrm{~min}$ at $4^{\circ} \mathrm{C}$ to obtain "postheparin plasma." This was then immediately aliquotted and stored at $-70^{\circ} \mathrm{C}$ until assay. The lipase assay is a modification of the method of Krauss (22). This method utilizes a sonified substrate of glycerol tri[9,10(n)${ }^{3} \mathrm{H}$ ]oleate (Amersham Corp., Arlington Heights, IL), unlabeled triolein $4 \mathrm{mg} / \mathrm{ml}$ and Triton X-100 $0.08 \% \mathrm{vol} / \mathrm{vol}$ in a $0.1 \mathrm{M}$ Tris- $\mathrm{HCl}$ buffer, $\mathrm{pH}$ 8.6. Duplicate $20-\mu \mathrm{l}$ aliquots of postheparin plasma are incubated for $1 \mathrm{~h}$ at $4^{\circ} \mathrm{C}$ with $25 \mu \mathrm{l}$ either of nonimmune rabbit serum or of a rabbit anti-human lipoprotein lipase (LPL) serum that inhibits LPL activity. $260 \mu \mathrm{l}$ of substrate is then added and the mixture incubated for $20 \mathrm{~min}$ at $37^{\circ} \mathrm{C}$. The reaction is stopped by a mixture of chloroform/methanol/heptane (1.37:1.28:1.0), and $\mathrm{K}_{2} \mathrm{CO}_{3}$ is added. Lipase activity is measured by the appearance of $\left[{ }^{3} \mathrm{H}\right]$ oleic acid in the aqueous phase and is given as micromoles free fatty acid liberated per milliliter plasma per hour. LPL activity is the difference between total activity and that remaining after antibody inhibition, whereas the latter is the hepatic lipase (HL) activity. A control postheparin plasma sample was run with each assay, and all results within a given assay were corrected by dividing by the ratio of the control results in that assay to the mean control results over 22 assays. If the control results in a given assay varied above or below the mean control results by $>23 \%$, all results from that assay were discarded, and the samples were retested. All lipase activity results presented are the mean of two to four separate assays. The coefficient of variation for the control results in the 22 standardizing assays was $12.7 \%$ for total lipase activity and $14.1 \%$ for HL activity. Similar coefficients of variation were obtained in a small number of subject samples which were also assayed repeatedly.

Statistical analysis. Linear regression analysis was performed using the least squares method, and statistical significance was defined as a $P$ value $<0.05$. Calculations were performed on The Rockefeller University Hospital CLINFO system.

\section{Results}

The age, body mass index, lipid, and lipoprotein levels were determined for each subject during the metabolic diet period (Table I). The subjects were selected to provide a wide range of HDL-C levels from $50 \mathrm{mg} / \mathrm{dl}$ upward. Mean HDL-C values ranged from 51 to $122 \mathrm{mg} / \mathrm{dl}$, and seven of the subjects (Nos. 1-6 and No. 8) were in the top quintile for age and sex (23). LDL-C, for which the subjects were not selected, also varied widely, from 70 to $532 \mathrm{mg} / \mathrm{dl}$, although only subjects 1,2 , and 7 had levels $>200 \mathrm{mg} / \mathrm{dl}$.
Table I. Lipid and Lipoprotein Levels*

\begin{tabular}{rrrrrrrr}
\hline & & $\begin{array}{c}\text { Body } \\
\text { mass }\end{array}$ & $\begin{array}{c}\text { Total } \\
\text { Subject }\end{array}$ & Age & index & \multicolumn{7}{l}{ cholesterol } & Triglycerides & VLDL-C & LDL-C & HDL-C \\
\hline & $y r$ & $k g / m^{2}$ & & & $m g / d l$ & & \\
1 & 34 & 24.5 & 442 & 90 & 21 & 299 & 122 \\
2 & 29 & 26.7 & 355 & 105 & 33 & 229 & 93 \\
3 & 33 & 17.4 & 194 & 59 & 13 & 92 & 90 \\
4 & 67 & 26.0 & 308 & 151 & 38 & 192 & 78 \\
5 & 22 & 26.9 & 221 & 96 & 24 & 125 & 72 \\
6 & 19 & 19.9 & 150 & 46 & 11 & 70 & 70 \\
7 & 64 & 22.2 & 639 & 111 & 37 & 532 & 70 \\
8 & 22 & 22.0 & 200 & 60 & 14 & 119 & 67 \\
9 & 22 & 20.5 & 223 & 87 & 31 & 131 & 61 \\
10 & 21 & 17.7 & 178 & 84 & 25 & 92 & 60 \\
11 & 24 & 27.6 & 159 & 56 & 10 & 91 & 58 \\
12 & 21 & 22.5 & 174 & 73 & 23 & 93 & 57 \\
13 & 21 & 23.8 & 167 & 59 & 16 & 95 & 56 \\
14 & 22 & 23.5 & 181 & 62 & 14 & 112 & 55 \\
15 & 79 & 18.5 & 180 & 126 & 51 & 78 & 51 \\
& & & & & & & \\
\hline
\end{tabular}

* Age, body mass index, lipid, and lipoprotein levels for each study subject are indicated.

After 2 wk of diet equilibration, purified, radiolabeled apo A-I and apo A-II were given to the subjects by intravenous bolus injection. Over the ensuing 2 wk a die-away curve of plasma radioactivity for each apolipoprotein for each subject was plotted. The apo A-I and apo A-II levels were measured and the metabolic parameters FCR and SR calculated as described in Methods. These results are presented in Table II. Wide ranges in each of these values also were seen. We evalu-

Table II. Plasma Levels, FCR, and SR of Apolipoproteins $A-I$ and $A-I I^{*}$

\begin{tabular}{cccccccc}
\hline & \multicolumn{3}{c}{ Apo A-I } & & \multicolumn{3}{c}{ Apo A-II } \\
\cline { 2 - 4 } \cline { 6 - 7 } Subject & Level & FCR & SR & & Level & FCR & SR \\
\hline & $m g / d l$ & pools/d & mg/kg per $d$ & & mg/dl & pools/d & mg/kg per $d$ \\
& & & & & & \\
1 & 251 & 0.133 & 13.4 & & 31.2 & 0.142 & 1.77 \\
2 & 191 & 0.162 & 8.9 & & 46.2 & 0.136 & 1.79 \\
3 & 175 & 0.151 & 11.9 & & 38.0 & 0.143 & 2.44 \\
4 & 181 & 0.221 & 13.1 & & 31.8 & 0.152 & 1.58 \\
5 & 162 & 0.189 & 12.8 & & 45.3 & 0.161 & 3.05 \\
6 & 158 & 0.176 & 13.7 & & 34.9 & 0.167 & 2.87 \\
7 & 163 & 0.185 & 12.0 & & 34.4 & 0.131 & 1.79 \\
8 & 155 & 0.171 & 9.3 & & 25.7 & 0.147 & 1.32 \\
9 & 153 & 0.184 & 10.0 & & 35.2 & 0.147 & 1.85 \\
10 & 162 & 0.242 & 14.1 & & 29.0 & 0.171 & 1.79 \\
11 & 171 & 0.227 & 14.0 & & 27.5 & 0.210 & 2.09 \\
12 & 127 & 0.233 & 10.0 & & 23.6 & 0.164 & 1.31 \\
13 & 137 & 0.256 & 10.3 & & 28.7 & 0.200 & 1.68 \\
14 & 134 & 0.195 & 10.1 & & 24.3 & 0.141 & 1.33 \\
15 & 134 & 0.291 & 13.3 & 26.7 & 0.205 & 1.86 \\
& & & & & & \\
\hline
\end{tabular}

* HDL apolipoprotein levels and metabolic parameters for each study subject are indicated. 
ated parameters of HDL composition and of endothelial lipase activity, since these are known to vary with HDL levels and may therefore relate to variability in HDL metabolism. An index of the ratio of core to surface components, and thereby of HDL particle size, may be obtained by dividing HDL-C, which predominantly reflects core cholesteryl ester, by the sum of apo A-I and apo A-II levels, which together account for $90 \%$ of the surface apoprotein. Since HDL particles are heterogeneous in the relative amounts of apo A-I and apo A-II, the ratio of plasma apo A-I to apo A-II level ratio provides a measure of this heterogeneity. Table III shows these indices of HDL composition and the postheparin plasma lipase activities during the metabolic diet.

Among the lipoprotein and apoprotein levels, a highly significant correlation was found between HDL-C and the apo A-I level $(r=0.93, P<0.001)$ and a positive trend of borderline significance between HDL-C and the apo A-II level ( $r$ $=0.47, P=0.07)$. The relation between apo A-I and apo A-II levels was not significant $(r=0.37, P=0.17)$.

Correlation analyses were performed to see which metabolic parameters best predicted levels of HDL-C, apo A-I, and apo A-II. HDL-C levels correlated inversely and highly significantly with apo A-I FCR $(r=-0.75, P<0.001)$ and also significantly with apo A-II FCR $(r=-0.54, P=0.036)$ (Fig. 1). HDL-C levels did not correlate significantly with the SR of either apo A-I or apo A-II ( $r=0.09$ and $r=-0.16$, respectively). Apo A-I levels correlated inversely and significantly with apo A-I FCR $(r=-0.64, P=0.01)$, but not significantly with apo A-I SR $(r=0.30, P=0.28)$ (Fig. 2). In contrast, apo A-II levels were not significantly correlated with apo A-II FCR ( $r=-0.38, P=0.16$ ) whereas they correlated strongly and directly with apo A-II SR $(r=0.65, P=0.009)$.

The interrelationships among the metabolic parameters of HDL were explored. Despite the wide range of the FCR values,

Table III. Parameters of HDL Composition and Postheparin Lipase Activities*

\begin{tabular}{|c|c|c|c|c|}
\hline Subject & HDL/A-I + A-II & A-I/A-II & LPL & $\mathrm{HL}$ \\
\hline & \multicolumn{2}{|c|}{ molar ratio } & \multicolumn{2}{|c|}{ umol/ml per $h$} \\
\hline 1 & 29.2 & 4.89 & 30.7 & 3.3 \\
\hline 2 & 25.3 & 2.51 & 15.3 & 10.5 \\
\hline 3 & 27.4 & 2.80 & 14.4 & 12.8 \\
\hline 4 & 24.2 & 3.46 & 21.1 & 17.8 \\
\hline 5 & 22.1 & 2.16 & 12.0 & 7.2 \\
\hline 6 & 23.5 & 2.74 & 11.3 & 9.9 \\
\hline 7 & 23.0 & 2.88 & 18.0 & 6.8 \\
\hline 8 & 24.5 & 3.67 & 13.1 & 7.5 \\
\hline 9 & 20.8 & 2.64 & 11.7 & 4.5 \\
\hline 10 & 20.8 & 3.39 & 12.5 & 9.0 \\
\hline 11 & 19.5 & 3.78 & 14.7 & 7.6 \\
\hline 12 & 24.9 & 3.27 & 20.0 & 10.1 \\
\hline 13 & 22.1 & 2.89 & 18.9 & 14.1 \\
\hline 14 & 22.9 & 3.36 & 21.1 & 16.6 \\
\hline 15 & 20.9 & 3.04 & 10.2 & 12.4 \\
\hline
\end{tabular}

* The ratio of HDL cholesterol to apo A-I plus apo A-II levels, the ratio of apo A-I to apo A-II levels, postheparin LPL, and endothelial $\mathrm{HL}$ activities for each study subject are indicated. for all but one of the subjects the apo A-I FCR was higher than the apo A-II FCR, and the mean of the former was significantly higher (mean \pm SD: $0.201 \pm 0.043$ vs. $0.161 \pm 0.026$, respectively, $P<0.001$ by paired $t$ test). The apo A-I FCR correlated well with the apo A-II FCR $(r=0.78, P<0.001)$, and the SR of apo A-I correlated with borderline significance with the SR of apo A-II $(r=0.49, P=0.06)$. However, the FCR did not correlate with the SR for either apo A-I or apo A-II $(r=0.20$ and 0.13 , respectively).

Correlations between apo A-I and apo A-II FCR and SR and two parameters of HDL composition, the HDL-C/apo A-I + apo A-II ratio and the apo A-I/apo A-II ratio, were next examined. The only significant correlations found were those between the FCRs of apo A-I and apo A-II and the HDL-C/ apo A-I + apo A-II ratio $(r=-0.69, P=0.005$ and $r=-0.61$, $P=0.015$, respectively) (Fig. 3 ).

Correlations of parameters of HDL metabolism and composition with postheparin LPL and HL activities were next examined. LPL did not correlate significantly with the FCR of apo A-I or of A-II $(r=-0.27, P=$ NS and $r=-0.40, P=0.13$, respectively) or with their SR $(r=-0.04, P=\mathrm{NS}$ and $r$ $=-0.45, P=0.09$, respectively). $\mathrm{HL}$ also failed to correlate significantly with apo A-I or apo A-II FCR ( $r=0.41$ and 0.14$)$ or SR $(r=-0.10$ and -0.22$)$ in these subjects. Despite the lack of correlation with the metabolic parameters, LPL activity did correlate with the HDL-C/A-I + A-II ratio $(r=0.61, P$ $=0.015)$ and with the apo A-I/apo A-II ratio $(r=0.68, P$ $=0.005)$. HL failed to correlate with the HDL-C/A-I + A-II ratio $(r=-0.04)$ or the A-I/A-II ratio $(r=-0.19)$.

One of the subjects (No. 1) was taking a medication to alter her sex hormone levels. Her regimen simply rendered her hormonal status like the postmenopausal subjects (Nos. 4, 7, 15), and we have not excluded her from the principle analyses. Nevertheless, to ensure she did not bias the results, we repeated the correlation analyses excluding her. The correlations of HDL-C with the FCR of apo A-I and apo A-II were essentially unchanged $(r=-0.72$ and $-0.60, P=0.004$ and 0.02 , respectively), as were those of HDL-C with the SR of apo A-I and apo A-II ( $r=-0.14$ and 0.32 , respectively). Similar small changes were seen in the correlation between apo A-I and apo A-II levels and the corresponding SR $(r=0.18$ and 0.65 , respectively) and FCR ( $r=-0.53$ and -0.40 , respectively). The correlations of the FCR of apo A-I and of apo A-II with the HDL-C/A-I + A-II ratio also differed little $(r=-0.59$ and -0.63 , respectively). The correlation between $\mathrm{LPL}$ and the HDL-C/A-I + A-II and A-I/A-II ratios, however, became nonsignificant ( $r=0.31$ for both relationships).

\section{Discussion}

The principal goal of this study was to clarify the mechanism responsible for high HDL-C levels. To avoid confounding variables known to affect HDL-C levels, our analysis is based upon data obtained in women consuming a metabolic diet, who were not consuming alcohol or taking exogenous estrogen. The simple metabolic model used to analyze our tracer data provides a good measure of overall metabolism of HDL while minimizing possible modeling artefacts. Although this method does not facilitate exploration of metabolic heterogeneity of HDL, it clearly delineates basic aspects of its metabolism. As with all turnover studies, interpretation of these data rests 

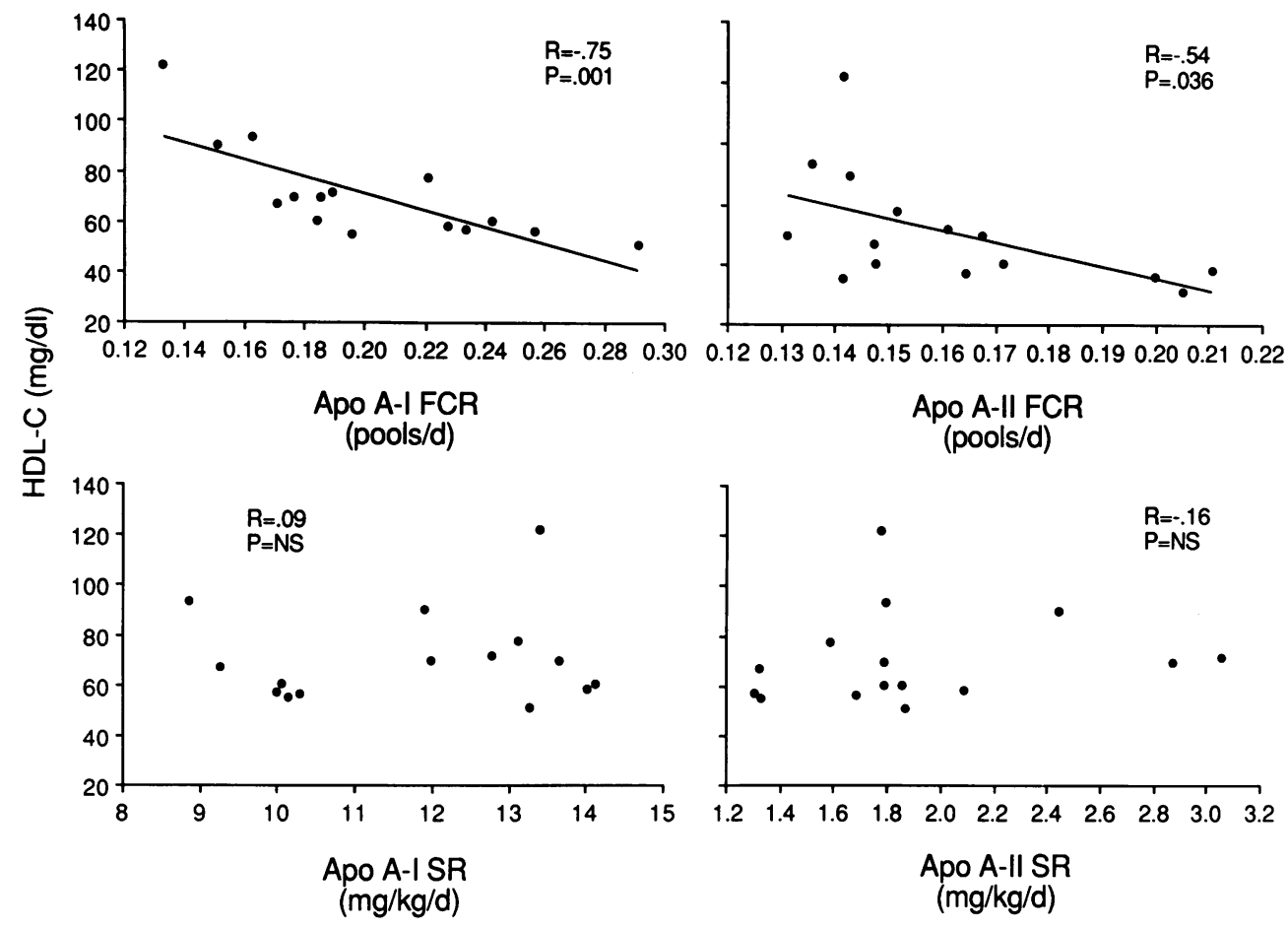

Figure 1. Relationship between levels of HDL-C $(\mathrm{mg} / \mathrm{dl})$ and apo A-I and apo A-II FCR (pools/d) and SR (mg/kg/d).

upon the assumption that the metabolism of the labeled tracer is equivalent to that of its unlabeled counterpart. We found that HDL-C levels correlated inversely with the FCR of apo A-I and apo A-II but not with the SR of either apoprotein. Plasma apo A-I levels also had a strong inverse correlation with apo A-I FCR but no significant correlation with apo A-I SR. In contrast, apo A-II levels did not correlate with apo A-II FCR but had a strong positive correlation with apo A-II SR.

There are few studies in the literature characterizing HDL apolipoprotein turnover parameters in high HDL-C subjects.
Fidge and co-workers (3) reported on one female subject with upper quintile HDL-C levels for age and sex. This person had a normal SR but an FCR in the lower range of normal for both apo A-I and apo A-II. Unfortunately, the normal comparison group was small, comprising just three female subjects. Rao and colleagues studied two women with high HDL-C levels, and one appeared to have an elevated SR, whereas the other had depressed FCR of both apo A-I and apo A-II (4). The normal control group, however, consisted of just two subjects. Schaefer and co-workers (5) studied one woman with border-
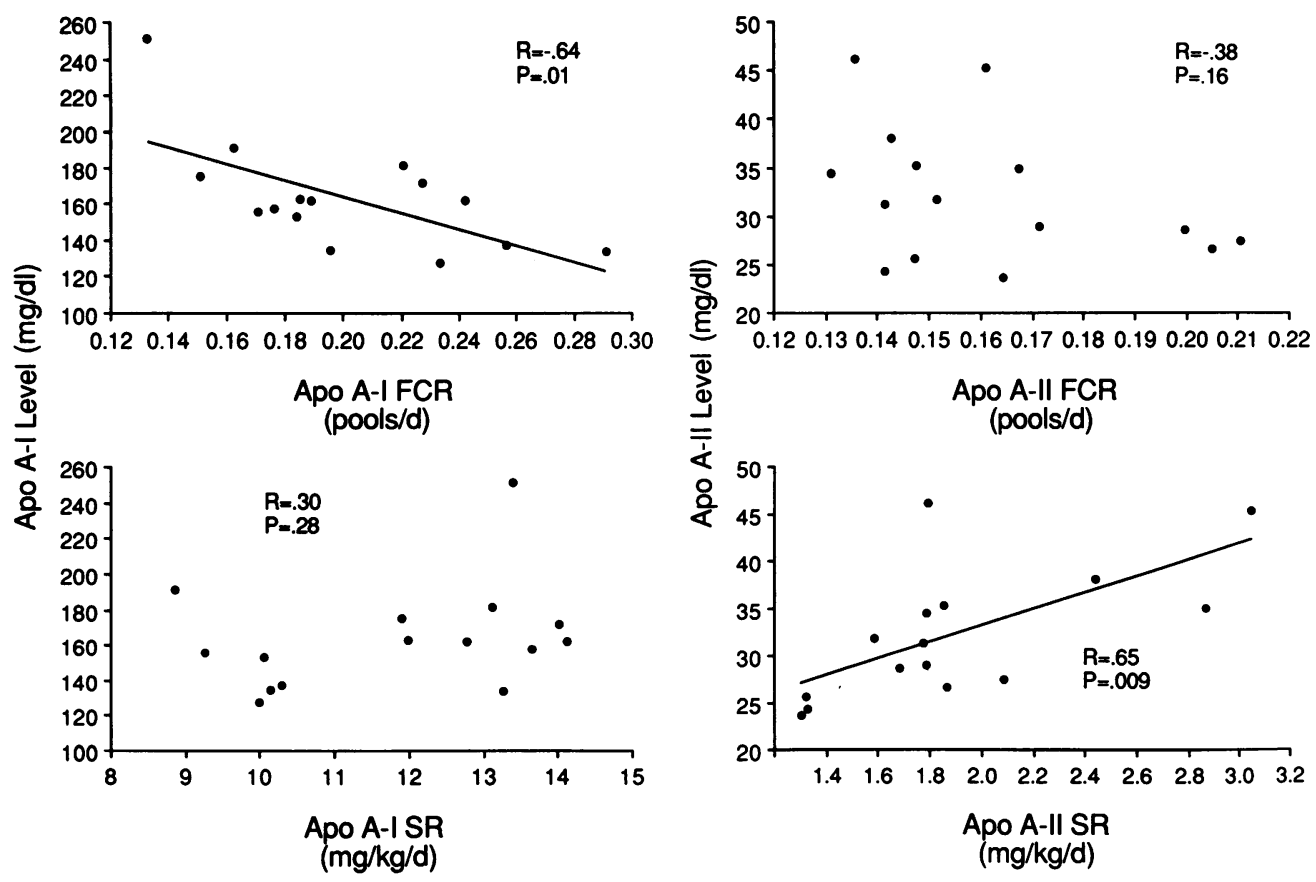

Figure 2. Relationship between apo A-I and apo A-II levels (mg/ $\mathrm{dl}$ ) and the respective apoprotein FCR (pools/d) and SR (mg/kg/ d). 

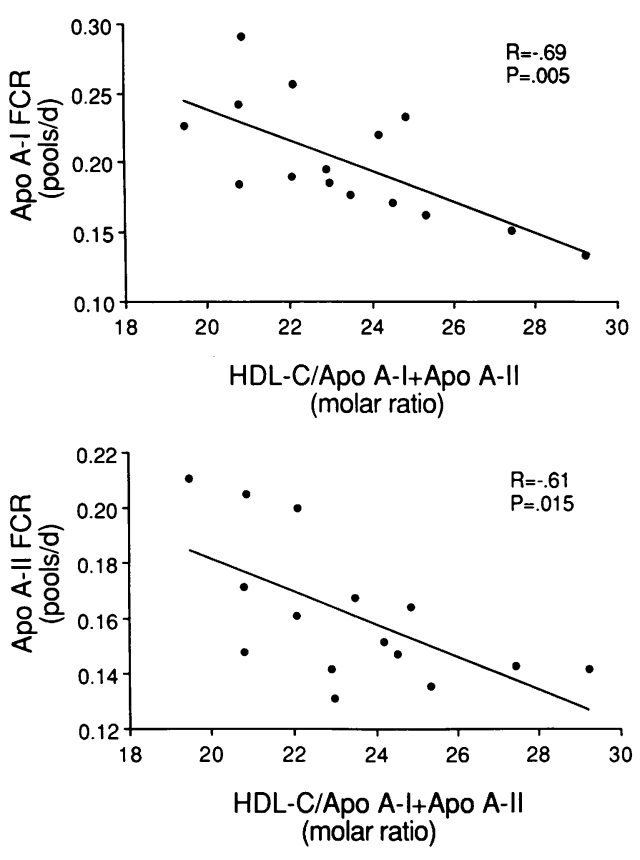

Figure 3. Relationship between apo A-I and apo A-II FCR (pools/d) and the HDL-C/A-I + A-II molar ratio.

line elevations of HDL-C levels and 10 controls. Her elevated apo A-I levels were associated with decreased apo A-I FCR and normal SR, while her level of apo A-II was normal, as were the apo A-II FCR and SR. Haffner and colleagues (6) reported studies on one high HDL-C female who appeared to have a low apo A-I and apo A-II FCR and a high apo A-I SR compared with metabolic parameters of normal subjects reported by other laboratories (6). However, the three normal females reported by the same laboratory showed sufficient variation in the metabolic parameters that the high HDL-C subject was within $1 \mathrm{SD}$ of the normal mean values. Thus, four of five high HDL-C women reported previously may have had decreased HDL apolipoprotein FCR. In the current study, seven of the subjects were in the top quintile of HDL-C for age and sex. The other eight subjects were in the middle three quintiles, although seven of these eight were clustered in the second quintile. Because neither the distribution of HDL-C nor of the HDL-C percentile was bimodal, we did not analyze our data by high and normal HDL-C groups. Nevertheless, correlation analysis of all 15 of our subjects together shows a strong and continuous inverse relationship between HDL-C and apo HDL FCR. These data, interpreted in the light of previous reports, strongly suggests that decreased HDL apolipoprotein FCR, rather than increased SR, is the predominant mechanism underlying high HDL-C levels in women. A similar mechanism appears to be the basis for high HDL-C levels in men (Brinton, E. A., S. Eisenberg, and J. L. Breslow, unpublished data).

The two major apolipoproteins in HDL are apo A-I and apo A-II, which comprise $\sim 70 \%$ and $20 \%$ of HDL protein, respectively. In this study as well as most previous ones, HDL-C levels correlated far better with apo A-I levels than with apo A-II levels. For this reason, our finding that HDL-C levels correlated more strongly with apo A-I FCR than with apo A-II FCR is not surprising (Fig. 1). The correlation between HDL-C and apo A-I levels also suggests that the latter would also be primarily regulated by apo A-I FCR; indeed, this is what was found (Fig. 2). Schaefer previously reported an inverse relationship between apo A-I levels and apo A-I FCR in subjects with normal HDL-C (5). The current study demonstrates that this relationship also holds for the upper range of HDL-C levels.

The second important implication of our data is that the predominant mechanisms of metabolic regulation of apo A-I and apo A-II levels greatly differ. Apo A-I levels correlate with apo A-I FCR but not with apo A-I SR, while apo A-II levels correlate with apo A-II SR but not with apo A-II FCR (Fig. 2). While certain differences in these relationships might be expected, given the lack of significant correlation between apo A-I and apo A-II levels, the strong divergence in apparent metabolic mechanisms is striking. This is especially so given that $(a)$ both apolipoproteins are frequently found on the same HDL particle, $(b)$ the FCR of apo A-I correlates strongly with the FCR of apo A-II, and $(c)$ there is a correlation of borderline significance between the SR of apo A-I and the SR of apo A-II. The differences between apo A-I and apo A-II metabolism might relate to the substantial heterogeneity of HDL particles. The simple modeling approach of this study does not test directly for metabolic heterogeneity. Possibly for this reason, our analysis does not provide an explanation of these intriguing disparities. Yet, since plasma levels of both apo A-I $(24,25)$ and apo A-II (26) are reported to correlate inversely with atherosclerosis risk, our data do suggest that both low apo A-I FCR and high apo A-II SR may play important roles in protection against atherosclerosis. Another, less striking, metabolic difference between apo A-I and apo A-II in this study is that the FCR of apo A-I is on average 25\% faster than the FCR of apo A-II $(P<0.0001)$. This confirms previous reports of other groups who have found the apo A-I FCR higher by $10-39 \%(3,5,6)$.

The current study may also provide some insight into the mechanism of regulation of HDL apolipoprotein FCR. A significant inverse relationship was found between the HDL-C/ A-I + A-II ratio and the FCR of apo A-I and apo A-II (Figure 3). Thus, larger HDL, with a greater core to surface ratio, may be catabolized more slowly. If this relationship is causal, it implies that lipid-rich HDL is less susceptible to catabolism. Lipid enrichment of HDL may alter apolipoprotein conformation (27), which could hide epitopes necessary for catabolism (28), as seen in the VLDL-IDL-LDL cascade (29-31). Alternatively, a primary decrease in HDL catabolism could result in extra lipid accumulation in HDL. This might happen by prolonged exposure to potential lipid sources, such as chylomicrons or peripheral tissues.

HDL-C levels have been correlated directly with levels of LPL $(32,33)$ and inversely with HL (33-35). It has been shown that LPL favors the formation of large lipid-rich $\mathrm{HDL}, \mathrm{HDL}_{2}$, from small lipid-poor $\mathrm{HDL}_{3}(36,37)$ and the opposite for $\mathrm{HL}$ $(38,39)$. In our study, we sought a relationship between HDL-C levels and HDL apolipoprotein SRs and FCRs and postheparin lipase levels. Neither the SR nor FCR of HDL apolipoproteins correlated with either LPL or HL. The relationship of HDL apolipoprotein turnover parameters and postheparin plasma lipase activities has been evaluated in four previous studies. Haffner and coworkers found that an androgenic hormone (stanozolol) induced a threefold increase in HL which coincided with, but did not correlate with, increased HDL apolipoprotein FCR (6). One of the subjects in that re- 
port also was studied on estrogen therapy, during which she had a $63 \%$ drop in HL, a $42 \%$ decrease in apo A-I FCR, and a $37 \%$ decline in apo A-I SR, with little change in LPL or the metabolism of apo A-II (40). In a contrasting study of five women, Schaefer and colleagues (41) reported a $44 \%$ decrease in HL with estrogen treatment but found only an increase in HDL apoprotein synthetic rate and no change in FCR. Saku and colleagues (42) found that a gemfibrozil-induced increase in LPL correlated with increased apo A-I and apo A-II SR. The same laboratory in a related study reported a positive correlation of apo A-I and apo A-II FCR with postheparin plasma HL in a cross-sectional study of hypertriglyceridemic and normal subjects (43). The lack of significant correlation between HL activity and apo HDL FCR in our study suggests that variability in HL activity may be less important in controlling HDL metabolism in subjects with high HDL-C levels.

It is of interest to consider the relationship of HDL apolipoprotein metabolic parameters to coronary heart disease (CHD) risk. It has been argued that since women have higher HDL-C levels and apo A-I SR but lower CHD risk than men that an increase in HDL apo A-I synthesis may protect against CHD. In our study in women, high HDL-C levels appear to be determined by reduced apo A-I FCR and we infer that variability in apo A-I FCR is more closely associated with CHD risk. Two previous observations may favor this inference. The administration of exogenous estrogen, which increases HDL-C levels and apo A-I SR (41), may increase rather than decrease CHD risk, at least in men with established atherosclerosis (44). In addition, saturated fat feeding in humans increases HDL-C levels by increasing apo A-I SR (Brinton, E. A., S. Eisenberg, and J. L. Breslow, unpublished data) and is known to increase rather than decrease CHD risk $(45,46)$. Since individuals with elevated HDL-C levels are known to be at reduced risk of atherosclerosis, our data suggest that reduced fractional clearance of apo A-I and apo A-II, and thus possibly of the entire HDL particle, may be an important metabolic mechanism of this protection.

\section{Acknowledgments}

The authors are indebted to Dr. John Albers for performing the apolipoprotein A-II assays, to Dr. Rudolf Zechner for establishing the lipase assay, and to Drs. Margo Denke and Li-Shin Huang for establishing the apolipoprotein A-I assay. The authors thank Dr. Nassar Khan, Ms. Michelle Estilo, Ms. Margie Timmons, Ms. Katie Tsang, and Ms. Bahareh Sahami for expert technical assistance, Ms. Lori Cersosimo, and Ms. Alexandra McNear for clerical expertise, and the turnover subjects for their patience and cooperation.

This work was supported in part by grants from the National Institutes of Health (HL-33714, HL-32435, HL-36461, CA-29502), a Clinical Investigator Award (HL-02034), and a General Clinical Research Center grant (RR-00102), in addition to a grant from the Bankers Trust Company Group, as well as general support from the Pew Trusts. Dr. Jan L. Breslow is an Established Investigator of the American Heart Association.

\section{References}

1. Miller, G. J., and N. E. Miller. 1975. Plasma-high-density-lipoprotein concentration and development of ischaemic heart-disease. Lancet. $i: 16-19$.

2. Albers, J. J., P. W. Wahl, V. G. Cabana, W. R. Hazzard, and J. J. Hoover. 1976. Quantitation of apolipoprotein A-I of human plasma high density lipoprotein. Metab. Clin. Exp. 25:633-644.
3. Fidge, N., P. Nestel, T. Ishikawa, M. Reardon, and T. Billington. 1980. Turnover of apoproteins A-I and A-II of high density lipoprotein and the relationship to other lipoproteins in normal and hyperlipidemic individuals. Metab. Clin. Exp. 29:643-653.

4. Rao, S. N., P. J. Magill, N. E. Miller, and B. Lewis. 1980. Plasma high-density lipoprotein metabolism in subjects with primary hypertriglyceridaemia: altered metabolism of apoproteins AI and AII. Clin. Sci. (Lond.). 59:359-367.

5. Schaefer, E. J., L. A. Zech, L. L. Jenkins, T. J. Bronzert, E. A. Rubalcaba, F. T. Lindgren, R. L. Aamodt, and H. B. Brewer, Jr. 1982. Human apolipoprotein A-I and A-II metabolism. J. Lipid Res. 23:850-862.

6. Haffner, S. M., R. S. Kushwaha, D. M. Foster, D. ApplebaumBowden, and W. R. Hazzard. 1983. Studies on the metabolic mechanism of reduced high density lipoproteins during anabolic steroid therapy. Metab. Clin. Exp. 32:413-420.

7. Bilheimer, D. W., S. Eisenberg, and R. I. Levy. 1972. The metabolism of very low density lipoprotein proteins. I. Preliminary in vitro and in vivo observations. Biochim. Biophys. Acta. 260:212-221.

8. McFarlane, A. S. 1958. Efficient trace-labelling of proteins with iodine. Nature (Lond.). 182:53.

9. Center for Drug Evaluation and Research. 1987 (December). Guideline on validation of the limulus amebocyte lysate test as an end-product endotoxin test for human and animal parenteral drugs, biological products, and medical devices. Food and Drug Administration, Rockville, MD.

10. Patterson, B. W., and A.-M. Lee. 1986. Self-association and phospholipid binding properties of iodinated apolipoprotein A-I. Biochemistry. 25:4953-4957.

11. The Lipid Research Clinics Population Studies Data Book. 1982. The Prevalence Study - Nutrient Intake. Volume II. U. S. Department of Health and Human Services, National Institutes of Health, Bethesda, MD. NIH Publication No. 80-2014.

12. National Health and Nutrition Examination Survey. 1987 (July). Dietary intake and cardiovascular risk factors. Part II. Serum urate, serum cholesterol, and correlates. National Center for Health Statistics, Office of Health Research Statistics and Technology, U. S. Department of Health and Human Services, Hyattsville, MD. GPO No. 017-022-00821-1.

13. Harris, J. A., and F. G. Benedict. 1919. A biometric study of basal metabolism in man. Publication No. 279. Carnegie Institute, Washington, DC. J. B. Lippincott Co., Philadelphia.

14. Mahalko, J. R., and L. K. Johnson. 1980. Accuracy of predictions of long-term energy needs. J. Am. Diet. Assoc. 77:557-561.

15. Malmendier, C. L., C. Delcroix, and J. P. Ameryckx. 1983. In vivo metabolism of human apoprotein A-I-phospholipid complexes. Comparison with human high density lipoprotein-apoprotein A-I metabolism. Clin. Chim. Acta. 131:201-210.

16. Matthews, C. M. E. 1957. The theory of tracer experiments with ${ }^{131} \mathrm{I}$-labelled plasma proteins. Phys. Med. Biol. 2:36-53.

17. Warnick, G. R., J. Benderson, and J. J. Albers. 1982. Dextran sulfate- $\mathrm{Mg}^{2+}$ precipitation procedure for quantitation of high-densitylipoprotein cholesterol. Clin. Chem. 28:1379-1388.

18. Clinical Chemistry Standardization Section. 1985 (December). Lipid Standardization Programs of the Centers for Disease Control. Center for Environmental Health, Centers for Disease Control, Department of Health and Human Services, Atlanta, GA.

19. Garvey, J. S., N. E. Cremer, and D. H. Sussdorf. 1977. Methods in Immunology. Third edition. The Benjamin/Cummings Publishing Company, Reading, MA. 218-219.

20. Avrameas, S. 1969. Coupling of enzymes to proteins with glutaraldehyde. Immunochemistry. 6:43-52.

21. Cheung, M. C., and J. J. Albers. 1977. The measurement of apolipoprotein A-I and A-II levels in men and women by immunoassay. J. Clin. Invest. 60:43-50.

22. Krauss, R. M., R. I. Levy, and D. S. Fredrickson. 1974. Selective measurement of two lipase activities in postheparin plasma from 
normal subjects and patients with hyperlipoproteinemia. J. Clin. Invest. 54:1107-1124.

23. The Lipid Research Clinics Population Studies Data Book. 1980. The Prevalence Study. Volume I. U. S. Department of Health and Human Services, National Institutes of Health, Bethesda, MD. NIH Publication 80-1527.

24. Avogaro, P., G. Bittolo Bon, G. Cazzolato, and G. B. Quinci. 1979. Are apolipoproteins better discriminators than lipids for atherosclerosis? Lancet. i:901-903.

25. Frazen, J., and G. Fex. 1986. Low serum apolipoprotein A-I in acute myocardial infarction survivors with normal HDL cholesterol. Atherosclerosis. 59:37-42.

26. Fager, G., O. Wiklund, S.-O. Olofsson, L. Wilhelmsen, and G. Bondjers. 1981. Multivariate analyses of serum apolipoproteins and risk factors in relation to acute myocardial infarction. Arteriosclerosis 1:273-279.

27. Lux, S. E., R. Hirz, R. I. Shrager, and A. M. Gotto. 1972. The influence of lipid on the conformation of human plasma high density apolipoproteins. J. Biol. Chem. 247:2598-2606.

28. Richmond, J. F., M. T. Walsh, C. Glass, and D. Atkinson. 1988. Rat apolipoprotein A-I (A-I) epitope expression is influenced by lipid environment. Arteriosclerosis. 8:604a-605a. (Abstr.)

29. Tsao, B. P., L. K. Curtiss, and T. S. Edgington. 1982. Immunochemical heterogeneity of human plasma apolipoprotein B. J. Biol. Chem. 257:15222-15228.

30. Bradley, W. A., S.-L. C. Hwang, J. B. Karlin, A. H. Y. Lin, S. C. Prasad, A. M. Gotto, Jr., and S. H. Gianturco. 1984. Low-density lipoprotein receptor binding determinants switch from apolipoprotein $\mathrm{E}$ to apolipoprotein $\mathrm{B}$ during conversion of hypertriglyceridemic verylow-density lipoprotein to low-density lipoproteins. J. Biol. Chem. 259:14728-14735.

31. Krul, E. S., M. J. Tikkanen, T. G. Cole, J. M. Davie, and G. Schonfeld. 1985. Roles of apolipoproteins B and E in the cellular binding of very low density lipoproteins. J. Clin. Invest. 75:361-369.

32. Kekki, M. 1980. Lipoprotein-lipase action determining plasma high density lipoprotein cholesterol level in adult normolipaemics. Atherosclerosis. 37:143-150.

33. Sady, S. P., E. M. Cullinane, P. N. Herbert, M. A. Kantor, and P. D. Thompson. 1984. Training, diet and physical characteristics of distance runners with low or high concentrations of high density lipoprotein cholesterol. Atherosclerosis. 53:273-281.

34. Kuusi, T., P. Saarinen, and E. A. Nikkila. 1980. Evidence for the role of hepatic endothelial lipase in the metabolism of plasma high density lipoprotein ${ }_{2}$ in man. Atherosclerosis. 36:589-593.
35. Applebaum-Bowden, D., S. M. Haffner, P. W. Wahl, J. J. Hoover, G. R. Warnick, J. J. Albers, and W. R. Hazzard. 1985. Postheparin plasma triglyceride lipases: relationships with very low density lipoprotein triglyceride and high density lipoprotein ${ }_{2}$ cholesterol. Arteriosclerosis. 5:273-282.

36. Patsch, J. R., A. M. Gotto, Jr., T. Olivecrona, and S. Eisenberg. 1978. Formation of high density lipoprotein ${ }_{2}$-like particles during lipolysis of very low density lipoproteins in vitro. Proc. Natl. Acad. Sci. USA. 75:4519-4523.

37. Taskinen, M.-R., M. L. Kashyap, L. S. Srivastava, M. Ashraf, J. D. Johnson, G. Perisutti, D. Brady, C. J. Glueck, and R. L. Jackson. 1982. In vitro catabolism of human plasma very low density lipoproteins. Atherosclerosis. 41:381-394.

38. Shirai, K., R. L. Barnhart, and R. L. Jackson. 1981. Hydrolysis of human plasma high density lipoprotein ${ }_{2}$-phospholipids and triglycerides by hepatic lipase. Biochem. Biophys. Res. Commun. 100:591599.

39. Deckelbaum, R. J., S. Eisenberg, Y. Oschry, E. Granot, I. Sharon, and G. Bengtsson-Olivecrona. 1986. Conversion of human plasma high density lipoprotein-2 to high density lipoprotein-3. J. Biol. Chem. 261:5201-5208.

40. Hazzard, R. W., S. M. Haffner, R. S. Kushwaha, D. Applebaum-Bowden, and D. M. Foster. 1984. Preliminary report: kinetic studies on the modulation of high-density lipoprotein, apolipoprotein, and subfraction metabolism by sex steroids in a postmenopausal women. Metab. Clin. Exp. 33:779-784.

41. Schaefer, E. J., D. M. Foster, L. A. Zech, F. T. Lindgren, H. B. Brewer, Jr., and R. I. Levy. 1983. The effects of estrogen administration on plasma lipoprotein metabolism in premenopausal females. $J$. Clin. Endocrinol. Metab. 57:262-267.

42. Saku, K., P. S. Gartside, B. A. Hynd, and M. L. Kashyap. 1985. Mechanism of action of gemfibrozil on lipoprotein metabolism. $J$. Clin. Invest. 75:1702-1712.

43. Saku, K., P. S. Gartside, B. A. Hynd, S. G. Mendoza, and M. L. Kashyap. 1985. Apolipoprotein AI and AII metabolism in patients with primary high-density lipoprotein deficiency associated with familial hypertriglyceridemia. Metab. Clin. Exp. 34:754-764.

44. The Coronary Drug Project Research Group. 1970. The coronary drug project. JAMA (J. Am. Med. Assoc.). 214:1303-1313.

45. Karvonen, M. J. 1980 . Final results of the Helsinki dietary prevention study. Prog. Food Nutr. Sci. 4:27-32.

46. Liu, K., J. Stamler, M. Trevisan, and D. Moss. 1982. Dietary lipids, sugar, fiber, and mortality from coronary heart disease. Arteriosclerosis. 2:221-227. 